\title{
BODY BUILD IN INFANTS
}

\section{The Proportions of the External Dimensions of the Healthy INFANT dURINg the First Year of Life}

By HARRY BAKWIN AND RUTH MORRIS BAKWIN

(From the Department of Diseases of Children, New York University and Bellevue Hospital Medical College, The Children's Medical Service, Bellevue Hospital and

The Fifth Avenue Hospital, New York)

(Received for publication January 30, 1931)

Measurements of the external dimensions of healthy infants were made in order to establish curves of central tendency with which to compare sick infants. This report comprises a description of the methods employed for statistical analysis and for the presentation of data and a comparison of 2 groups of healthy infants from different social environments.

This series consists of over 18,000 measurements on 646 infants under 1 year of age of whom 303 were males and 343 females. In addition more than 1200 newborn infants have been measured. Data on these are not reported here.

The infants used in this series were healthy in the sense in which this term is generally used, i.e. they were not suffering from acute or chronic illness nor were they strikingly underweight.

Only infants of Caucasian antecedants have been included. The technique for making measurements of the external dimensions of infants has been described in detail in the preceding paper (1).

Except in occasional instances the entire series of measurements (30 in all) was made on each patient. Measurements of the head during the first 3 days of life have not been included in the graphs or calculations because of distortion due to head molding at birth. A series of head measurements on infants during the second week of life has been substituted for those omitted. Chest measurements during the first 3 days of life have been excluded because of the fluctuations in size incident to the establishment of the respiratory function in the newborn (2). 
This series is made up of 2 groups of infants which will hereafter be designated as Group A and Group B.

\section{DESCRIPTION OF GROUP A INFANTS}

Group A consists of 475 infants, most of whom were born at the Fifth Avenue Hospital and observed repeatedly in a special clinic. A small number of patients from private practice (25 infants measured 42 times) are included in this group.

With few exceptions the income of the parents varied only slightly, ranging between $\$ 30$ and $\$ 35$ per week (in 1929).

Most of the infants were partially or completely breast-fed from 3 to 6 months. All patients from private practice and all those attending regularly the special clinic at the Fifth Avenue Hospital received cod liver oil and orange juice after the age of 3 weeks, egg yolk, and vegetable or cereal by the fourth month.

All infants used in this study were born in the United States. In order to study the influence of race on the proportions of the external dimensions of the body, Group A infants were divided into 4 groups by descent, North European, consisting of Irish, Scotch, English, German, Scandinavian and Finnish (234 infants); Central European, consisting of French, Hungarian, Rumanian, Polish, Czecho-Slovakian and Austrain (20 infants); Mediterranean, consisting of South Italian, Greek, Turkish and Spanish (126 infants); and infants of Russian and Polish-Jewish descent (106 infants). In a small group the race could not be ascertained with any degree of accuracy.

The dimensions of the infants in each of the 4 groups were compared, in relation to body length, with the total group by means of scatter diagrams for cephalic breadth, diameter of face (bimalar), bigonial diameter, circumference of thorax, biacromial diameter, bicristal diameter and length of radius. In no instance were differences in the proportions of the external dimensions.apparent.

In table 1 the proportions of several dimensions to total body length are compared for North European, Jewish and Mediterranean infants. Averages, standard deviations and probable errors are shown in relation to total body length. Differences in the various dimensions of infants of each of the racial groups and the probable errors of the differences are also included. The differences are small and vary 


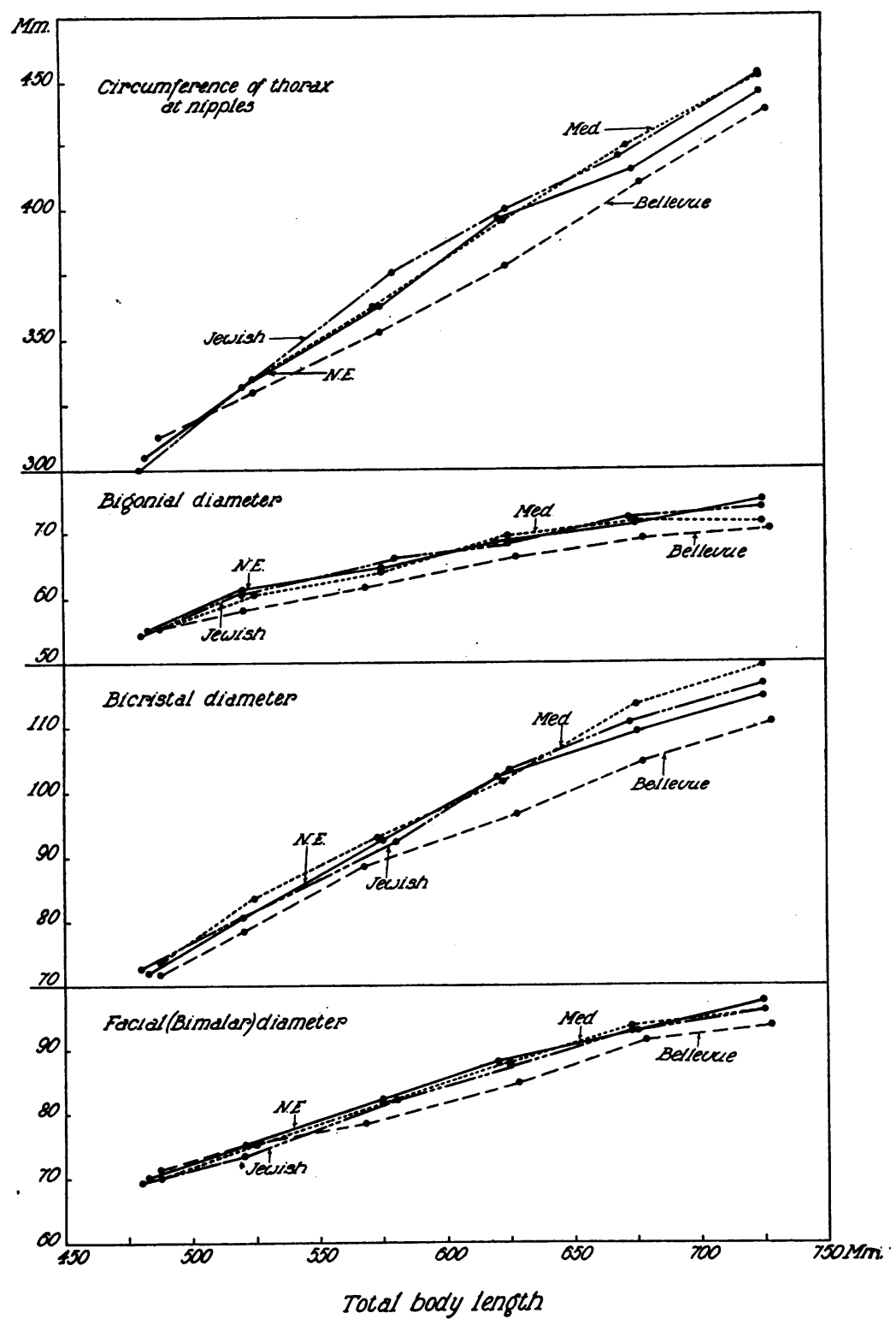

Chart 1.' The Influence of Race on Various External Dimensions or Intants DuRINg the First Year of LIFe in Relation to Total Body Length

The line marked N.E. connects the average points for infants of North European parentage; Med., infants of Mediterranean parentage, etc. 


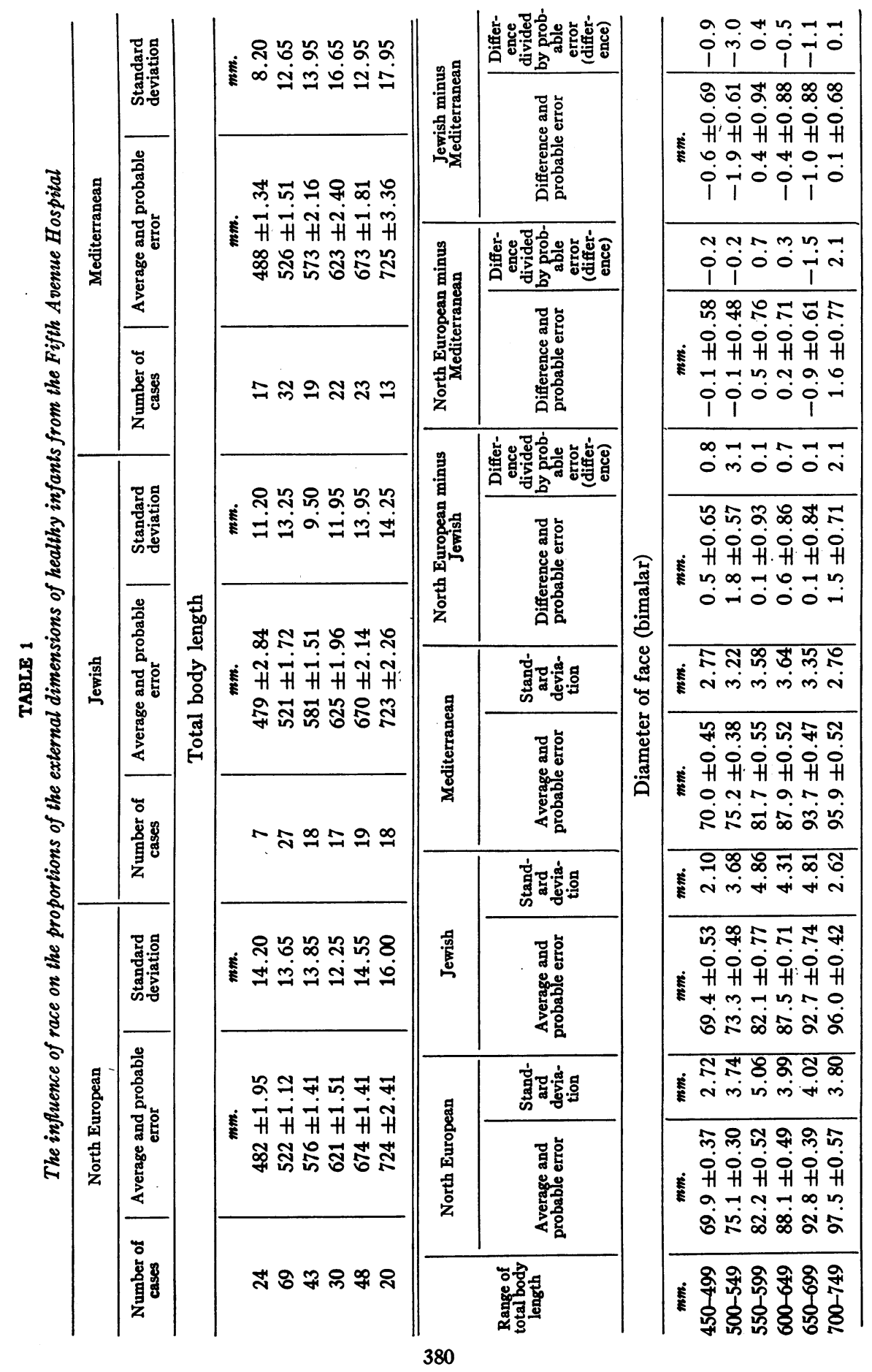




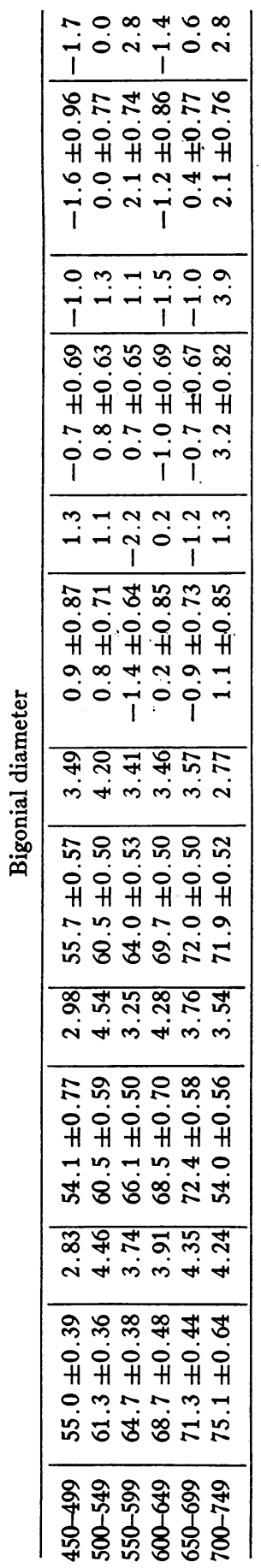

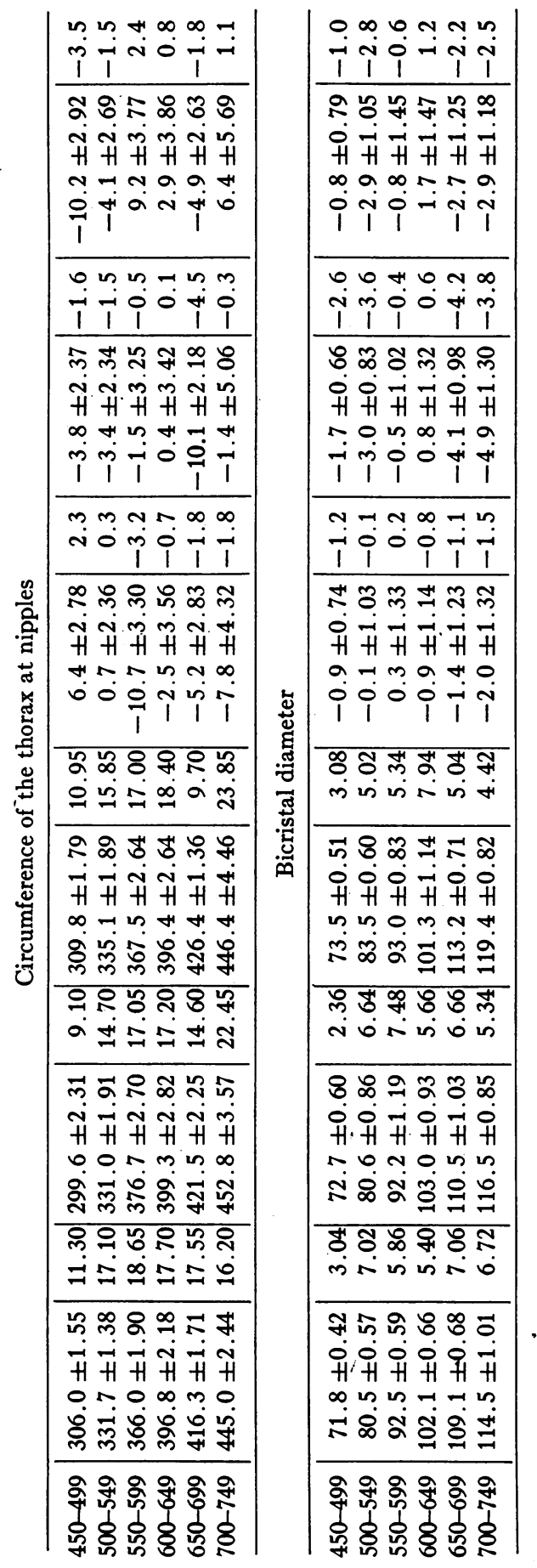


from one another irregularly. These results are illustrated in chart 1. The average lines for the Bellevue Hospital infants are consistently lower than the lines for each of the racial groups of Fifth Avenue Hospital infants.

In this series, therefore, no significant differences were apparent in the proportions of the various body dimensions to total body length in the three racial groups studied. It is possible that, in a larger series, differences might be found. The series is sufficiently large, however, to show that an environmental factor may influence body build.

All averages were calculated separately for sex. The males are significantly larger, relative to stature, in the hand and foot dimensions, and in the upper facial height. These differences have been treated statistically, in a manner similar to that used for comparison of infants of various racial groups, but calculations are not included in this report.

\section{DESCRIPTION OF GROUP B INFANTS}

Group B consists of 171 healthy infants admitted to the wards of Bellevue Hospital either as foundlings or because of illness of the mothers.

The incomes of the parents in the Bellevue district are very small, ranging between $\$ 15$ and $\$ 22$ per week (in 1929). Unemployment is common.

There was no control of the diets before admission to the hospital. Most of the infants in the Bellevue district are artificially fed from early life. The intake of energy-yielding foods is often inadequate. Small amounts of orange juice are given, but only rarely cod liver oil.

It was not possible to ascertain the descent of most of the infants because of the large proportion of foundlings. The healthy Bellevue infants are mainly of Irish descent.

GROWTH IN WEIGHT DURING THE FIRST YEAR OF LIFE

In chart 2 the weights of Group A and Group B infants are compared in relation to age during the first year of life. Age in weeks is represented as the abscissa, weight as the ordinate. The continuous line is the weight-age curve given by Holt and Howland for healthy 


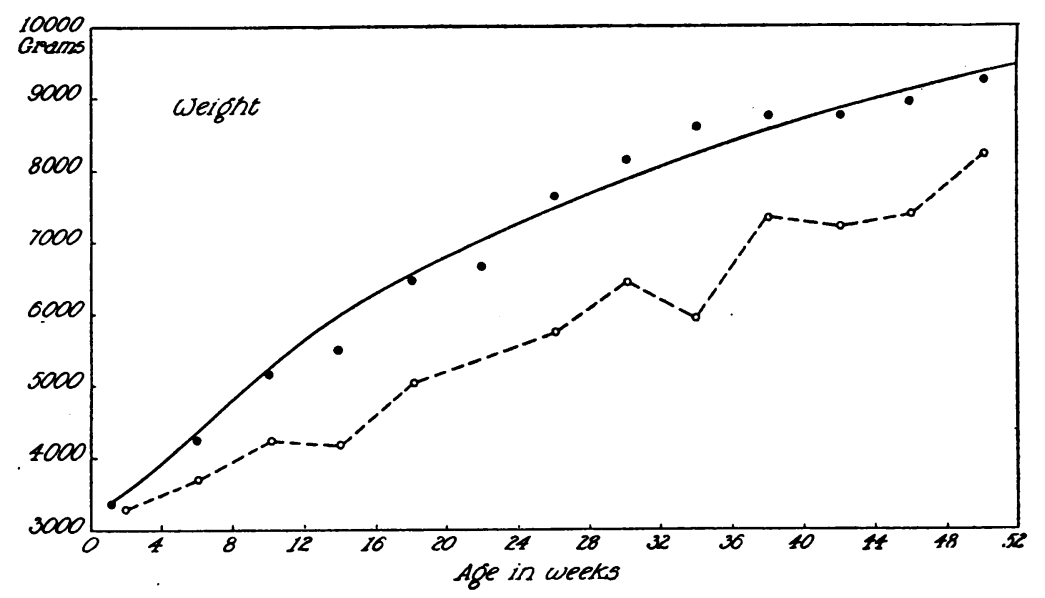

Chart 2. Weight Curve During the First Year of Life

The continuous line is the age-weight curve for healthy infants given by Holt and Howland. The dots represent averages for the Fifth Avenue Hospital infants, circles connected by the broken line, Bellevue Hospital infants.

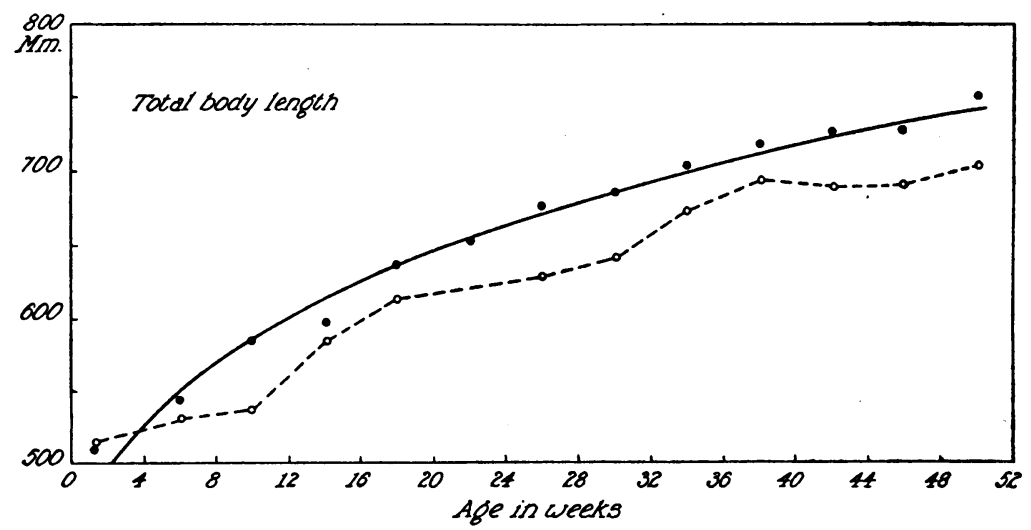

Chart 3. Growth of Total Body Length During the First Year of Life

The continuous line is the curve of central tendency calculated according to the formula given in the text. The dots represent averages for the Fifth Avenue Hospital infants, the circles connected by the broken line, Bellevue Hospital infants.

infants (3). The dots represent average weights for the Group A infants, the circles connected by the dotted line averages for the Group B infants. The Group A infants follow the normal curve closely. 
The Group B infants, after the first month of life, fall far below. The irregularity in the distribution of the averages for this group is due, in part to the small number of cases (no foundlings are included since the ages are unknown excepting those admitted during the new born period), and in part to a selective death rate, the thin babies dying at an earlier age than the heavier ones.

GROWTH IN TOTAL BODY LENGTH DURING THE FIRST YEAR OF LIFE

In chart 3 the total body length of Group A and Group B infants are compared by age. Age in weeks is represented as the abscissa, total body length as the ordinate. The continous line is the curve of central tendency for increase of total body length in relation to age during the first year of life for Group A infants. The dots represent averages of total body length for Group A infants, the circles, connected by the dotted line, averages for the Group B infants. After the second month of life the Group B infants fall below the curve of central tendency, indicating a retardation in growth of total body length.

The empirical formula for this curve, computed by the method of least squares, is,

$$
L=493+1.2 T+170 \log (0.25 T+0.5) .
$$

where $L$ represents total body length in mm., and $T$ age in weeks. From this formula and the empirical formulae given in table 2 for the relationship between the various external dimensions and total body length, empirical formulae for the relationship bettween various dimensions and age can be readily computed. Thus for facial diameter, where $F$ represents facial diameter,

$$
F=0.107 L+20.4
$$

Transposing (2),

$$
L=\frac{F-20.4}{0.107}
$$

Substituting, $\frac{F-20.4}{0.107}$ for $L$ in (1) we have,

$$
F=73.3+0.128 T+18.20 \log (0.25 T+0.5) \text {. }
$$


GROWTH OF THE EXTERNAL DIMENSIONS OF THE BODY IN RELATION TO TOTAL BODY LENGTH

The method used for presenting the data on growth of the external dimensions in relation to total body length is essentially the same as that used by Scammon and Calkins in their study of growth in the fetal period (4). The advantages of using total body length rather than sitting height as a base are discussed by Scammon and Calkins (4).

Scatter diagrams were constructed for each dimension with stature represented as the abscissa and the dimension in question as the ordinate. The data for each dimension were then divided into 6 groups on the basis of stature, each group representing a $50 \mathrm{~mm}$. interval. Numerical averages for both stature and the dimension in question were calculated for each of the 6 groups and these averages were used in the derivation of empirical formulae for the curves of central tendency.

It appeared that the dimensions measured could be adequately represented by straight line curves when plotted in relation to total body length. Curves have been computed only for infants under $750 \mathrm{~mm}$. in total body length.

Scatter diagrams and curves of central tendency for the relationship, in Group A infants, between total body length and diameter of face (bimalar), bigonial diameter, biacromial diameter of trunk, circumference of thorax at the nipples and bicristal diameter are shown in chart 4. Dots represent measurements on female infants, circles on males. The continuous lines are the curves of central tendency plotted according to the empirical formulae given in table 2.

In table 2 are shown the constants in the empirical formulae for the curves of central tendency of the dimensions listed in the first paper of this series (1). The formulae, with the exception of those for facial diameter (bimalar), bigonial diameter, circumference of thorax at nipples, and bicristal diameter were computed on the basis of measurements on 320 infants from the Fifth Avenue Hospital and 61 infants from Bellevue Hospital.

The compilation of these data was made originally on 320 healthy infants from the Fifth Avenue Hospital and 61 healthy infants from Bellevue Hospital. When differences were found in the proportions of the body dimensions of the 2 groups it 
became apparent that they could not be treated together. In the meantime more measurements had been made at both hospitals and the original series, enlarged by the addition of the new measurements, has been used in this paper except when otherwise stated. Having two groups of infants from two hospitals,

TABLE 2

Constants in empirical formulae $(y=a x+b) *$ for computing the curves of central tendency from total body length

\begin{tabular}{|c|c|c|}
\hline \multirow{2}{*}{ Dimension } & \multicolumn{2}{|c|}{ Constants } \\
\hline & a & b \\
\hline Sitting height $\ldots \ldots \ldots \ldots \ldots \ldots \ldots \ldots \ldots \ldots \ldots$ & 0.545 & 71.6 \\
\hline Circumference of head $\ldots \ldots \ldots \ldots \ldots \ldots \ldots \ldots \ldots$ & 0.458 & 118 \\
\hline Cephalic length.$\ldots \ldots \ldots \ldots \ldots \ldots \ldots \ldots \ldots \ldots \ldots$ & 0.127 & 55 \\
\hline Cephalic breadth $\ldots \ldots \ldots \ldots \ldots \ldots \ldots \ldots \ldots \ldots$ & 0.154 & 14.5 \\
\hline Diameter of face (bimalar) $\ldots \ldots \ldots \ldots \ldots \ldots \ldots$ & 0.107 & 20.4 \\
\hline Bigonial diameter. $\ldots \ldots \ldots \ldots \ldots \ldots \ldots \ldots \ldots$ & 0.074 & 21.5 \\
\hline Upper facial height (nasion-prosthion) $\ldots \ldots \ldots \ldots \ldots \ldots$ & 0.039 & 12.4 \\
\hline 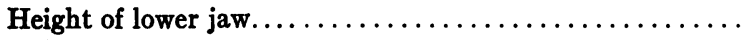 & 0.028 & 3.8 \\
\hline 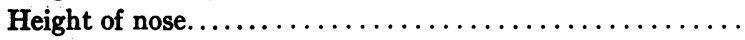 & 0.026 & 8.8 \\
\hline 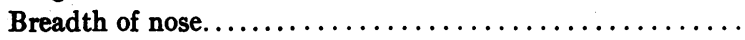 & 0.017 & 12.9 \\
\hline Inter-inner canthus diameter. $\ldots \ldots \ldots \ldots \ldots \ldots \ldots$ & 0.016 & 14.1 \\
\hline 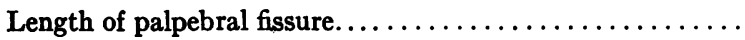 & 0.024 & 8.1 \\
\hline Length of ear. $\ldots \ldots \ldots \ldots \ldots \ldots \ldots \ldots \ldots \ldots$ & 0.053 & 9.6 \\
\hline 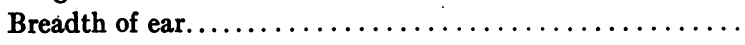 & 0.024 & 12.7 \\
\hline Circumference of thorax at the nipples.......... & 0.562 & 42 \\
\hline 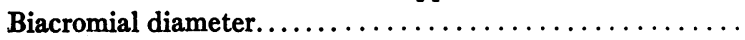 & 0.239 & -9.6 \\
\hline Bicristal diameter................... & 0.168 & -4.3 \\
\hline 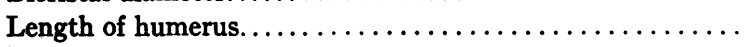 & 0.164 & 2.3 \\
\hline Length of radius..... & 0.116 & 12.1 \\
\hline Length of hand..... & 0.095 & 16.2 \\
\hline Length of palm... & 0.055 & 8.7 \\
\hline Breadth of palm.............. & 0.043 & 9.8 \\
\hline Length of middle finger........ & 0.040 & 13.5 \\
\hline Length of tibia..... & 0.170 & 5.4 \\
\hline Length of thigh. . & 0.247 & -7.9 \\
\hline Height of foot... & 0.059 & -5.8 \\
\hline Length of foot... & 0.121 & 15.8 \\
\hline Breadth of foot. $\ldots \ldots \ldots \ldots \ldots \ldots \ldots \ldots \ldots \ldots \ldots \ldots \ldots \ldots \ldots \ldots$ & 0.053 & 4.0 \\
\hline
\end{tabular}

* $y$ equals the linear dimension in question; $x$ equals total body length; $a$ and $b$ are constants.

an old and a new group, permitted various checks to be made. Thus, the differences noted below in the proportions of the external dimensions of Group A and Group B infants have been checked on two different groups from Bellevue Hospital and 


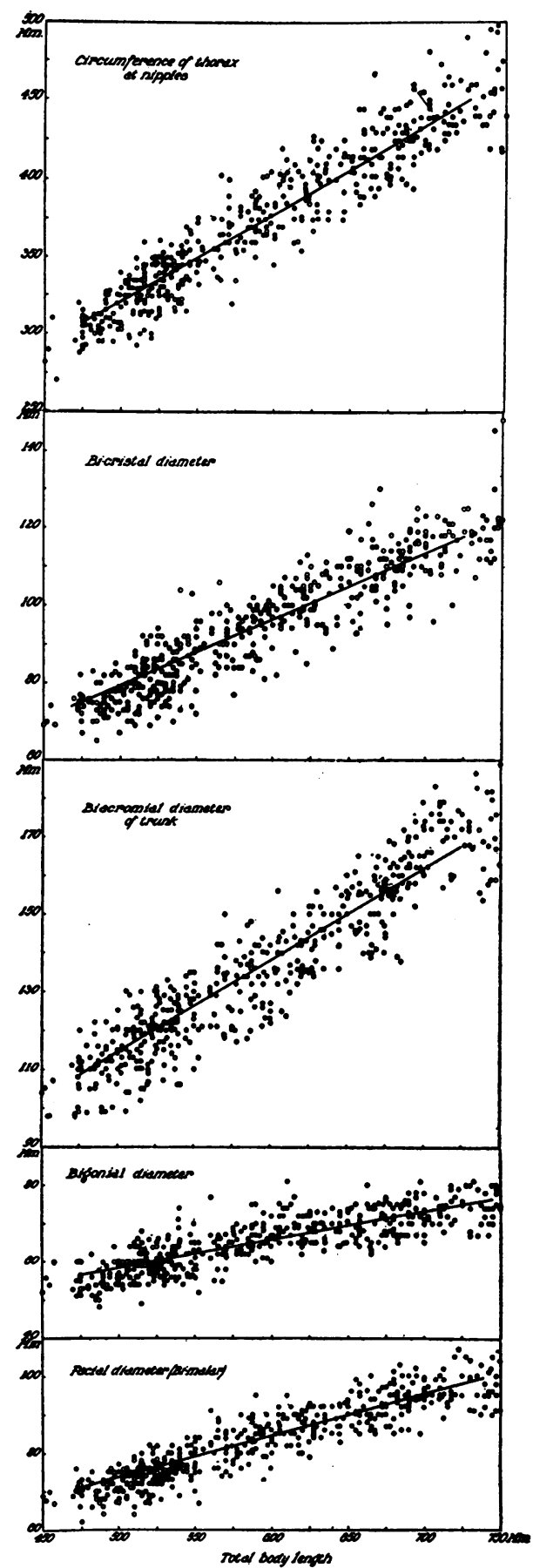

Chart 4. The Relationship Between total Body Length and Various Linear Dimensions During the First Year of Life

(Fifth Avenue Hospital Infants)

Dots represent individual measurements on females, the circles on males. The continuous lines are the curves of central tendency plotted according to the formulae given in table 2 . 
have been controlled by the absence of such changes when the new Fifth Avenue Hospital group has been compared with the old.

COMPARISON OF THE PROPORTIONS OF THE EXTERNAL DIMENSIONS OF HEALTHY INFANTS FROM THE FIFTH AVENUE AND BELLEVUE HOSPITALS

The 171 infants in Group B were compared for various dimensions with the curves of central tendency for Group A by means of scatter diagrams. No differences were found for the relative lengths of the following dimensions: circumference of head, cephalic length, cephalic breadth, upper facial height, length of humerus, radius, femur and tibia. Differences were noted for the facial diameter (bimalar), the bigonial diameter, the circumference of the thorax, the bicristal diameter, and the biacromial diameter, the Group B infants in each instance tending to fall below the curves of central tendency, indicating that the Group $B$ infants are relatively narrower in their transverse dimensions and chest than the Group A infants. These differences are not marked for infants below $550 \mathrm{~mm}$. in height; beyond this the difference tends to increase, approximating in most instances from 5 to 7 times the probable error. These results are shown in tables 3 and 4 and are illustrated graphically in charts 5 and 6 . Tables 3 and 4 include standard deviations and probable errors for each of the dimensions at various levels of total body length.

When comparisons were made of the biacromial diameter, it was found that the new measurements were larger than the old, both for the Fifth Avenue Hospital and the Bellevue Hospital infants, owing, presumably, to an unconscious change in the technique of measuring. Separate calculations of the biacromial diameter have therefore been made for the new groups of infants only, and are shown in table 4 and chart 6 .

Approximately fifty Bellevue Hospital infants, admitted when healthy and measured before the onset of illness, developed acute intestinal intoxication. These have not been included in the Group B series. As will be shown in a later paper, infants with this condition are smaller in their transverse diameters and chest circumference relative to stature, than are either Group A or Group B infants. Had these been included in the Bellevue group the discrepancy between it and the Fifth Avenue group would have been even greater. 
TABLE 3

Comparison of the proportions of the external dimensions of healthy infants from the Fifth Avenue and Bellevue Hospitals

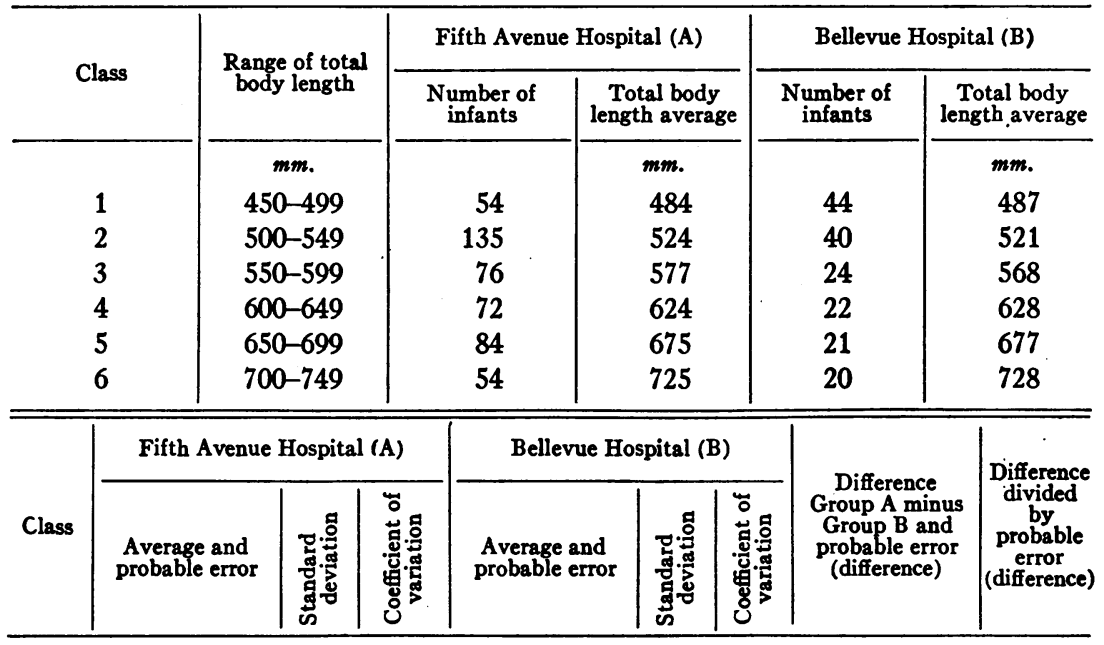

a. Diameter of face (bimalar)

\begin{tabular}{|c|c|c|c|c|c|c|c|c|}
\hline & $m m$. & $m m$. & per cent & $m m$. & $m m$. & $\begin{array}{l}\text { per } \\
\text { cent }\end{array}$ & $m m$. & \\
\hline 1 & $71.0 \pm 0.28$ & 3.03 & 4.2 & $70.8 \pm 0.29$ & 2.81 & 3.9 & $0.2 \pm 0.40$ & 0.5 \\
\hline 2 & $75.3 \pm 0.23$ & 3.99 & 5.3 & $75.3 \pm 0.44$ & 4.20 & 5.5 & $0.0 \pm 0.49$ & 0.0 \\
\hline 3 & $82.4 \pm 0.34$ & 4.38 & 5.3 & $78.3 \pm 0.58$ & 4.28 & 5.4 & $4.1 \pm 0.67$ & 6.1 \\
\hline 4 & $88.1 \pm 0.31$ & 3.95 & 4.5 & $84.8 \pm 0.42$ & 2.89 & 3.4 & $3.3 \pm 0.52$ & 6.3 \\
\hline 5 & $93.9 \pm 0.37$ & 5.07 & 5.4 & $91.4 \pm 0.64$ & 4.35 & 4.7 & $2.5 \pm 0.74$ & 3.4 \\
\hline 6 & $97.4 \pm 0.37$ & 4.06 & 4.2 & $93.9 \pm 0.48$ & 3.15 & 3.3 & $3.5 \pm 0.61$ & 5.8 \\
\hline
\end{tabular}

b. Bigonial diameter

\begin{tabular}{l|r|r|r|r|r|r|r|r}
\hline 1 & $55.6 \pm 0.36$ & 3.91 & 7.0 & $54.1 \pm 0.28$ & 2.76 & 5.1 & $1.5 \pm 0.45$ & 3.3 \\
2 & $60.8 \pm 0.28$ & 4.78 & 7.7 & $58.0 \pm 0.45$ & 4.24 & 7.0 & $2.8 \pm 0.53$ & 5.3 \\
3 & $65.4 \pm 0.31$ & 4.05 & 6.2 & $61.6 \pm 0.62$ & 4.48 & 7.3 & $3.8 \pm 0.69$ & 5.5 \\
4 & $69.4 \pm 0.31$ & 3.79 & 5.4 & $66.2 \pm 0.62$ & 4.48 & 6.8 & $3.2 \pm 0.69$ & 4.7 \\
5 & $71.8 \pm 0.29$ & 3.90 & 5.4 & $69.3 \pm 0.47$ & 3.17 & 4.5 & $2.5 \pm 0.54$ & 4.6 \\
6 & $74.2 \pm 0.37$ & 4.09 & 5.5 & $70.8 \pm 0.49$ & 3.26 & 4.6 & $3.4 \pm 0.61$ & 5.6 \\
\hline \multicolumn{7}{c}{ c. Circumference of thorax at nipples } \\
\hline 1 & $308 \pm 1.10$ & 12.1 & 3.9 & $308 \pm 1.30$ & 12.1 & 3.2 & $0 \pm 1.70$ & 0.0 \\
2 & $334 \pm 0.93$ & 16.1 & 4.8 & $329 \pm 2.07$ & 19.4 & 5.9 & $5 \pm 2.27$ & 2.2 \\
3 & $369 \pm 1.48$ & 19.2 & 5.2 & $353 \pm 2.51$ & 18.9 & 5.4 & $16 \pm 2.91$ & 5.5 \\
4 & $397 \pm 1.42$ & 18.4 & 4.6 & $378 \pm 2.04$ & 14.5 & 3.8 & $19 \pm 2.56$ & 7.2 \\
5 & $422 \pm 1.37$ & 18.5 & 4.4 & $410 \pm 1.43$ & 9.6 & 2.3 & $12 \pm 1.98$ & 6.1 \\
6 & $450 \pm 1.87$ & 20.7 & 4.6 & $438 \pm 2.80$ & 18.5 & 4.2 & $12 \pm 3.37$ & 3.5 \\
\hline
\end{tabular}


TABLE 3-Concluded

\begin{tabular}{|c|c|c|c|c|c|c|c|c|}
\hline \multirow[b]{2}{*}{ Class } & \multicolumn{3}{|c|}{ Fifth Avenue Hospital (A) } & \multicolumn{3}{|c|}{ Bellevue Hospital (B) } & \multirow[b]{2}{*}{$\begin{array}{c}\text { Difference } \\
\text { Group A minus } \\
\text { Group B and } \\
\text { probable error } \\
\text { (difference) }\end{array}$} & \multirow{2}{*}{$\begin{array}{c}\text { Difference } \\
\text { divided } \\
\text { by } \\
\text { probable } \\
\text { error } \\
\text { (difference }\end{array}$} \\
\hline & $\begin{array}{l}\text { Average and } \\
\text { probable error }\end{array}$ & 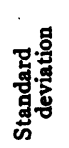 & 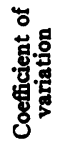 & $\begin{array}{l}\text { Average and } \\
\text { probable error }\end{array}$ & 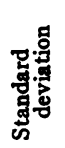 & 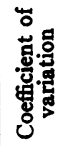 & & \\
\hline
\end{tabular}

d. Bicristal diameter

\begin{tabular}{|c|c|c|c|c|c|c|c|c|}
\hline & $m m$. & $m m$. & per cent & $m m$. & $\mathrm{mm}$. & $\underset{\substack{\text { per } \\
\text { cent }}}{ }$ & $\mathrm{mm}$. & \\
\hline 1 & $75.4 \pm 0.40$ & 4.30 & 5.7 & $71.8 \pm 0.70$ & 6.86 & 9.5 & $3.6 \pm 0.81$ & 4.4 \\
\hline 2 & $81.6 \pm 0.40$ & 6.72 & 8.2 & $78.3 \pm 0.74$ & 6.88 & 8.8 & $3.3 \pm 0.84$ & 3.9 \\
\hline 3 & $93.5 \pm 0.51$ & 6.54 & 7.0 & $88.7 \pm 0.91$ & 6.68 & 7.5 & $4.8 \pm 1.04$ & 4.6 \\
\hline 4 & $101.7 \pm 0.53$ & 6.60 & 6.5 & $96.4 \pm 0.98$ & 6.78 & 7.0 & $5.3 \pm 1.11$ & 4.8 \\
\hline 5 & $110.7 \pm 0.53$ & 7.20 & 6.5 & $104.6 \pm 0.76$ & 5.12 & 4.9 & $6.1 \pm 0.93$ & 6.6 \\
\hline 6 & $117.2 \pm 0.59$ & 6.56 & 5.0 & $110.3 \pm 0.94$ & 6.22 & 5.6 & $6.9 \pm 1.11$ & 6.2 \\
\hline
\end{tabular}

TABLE 4

Comparison of the proportions of the biacromial diameters of healthy infants from the Fifth Avenue and Belleoue Hospitals

\begin{tabular}{|c|c|c|c|c|c|c|c|c|}
\hline \multirow[b]{2}{*}{$\begin{array}{c}\text { Range } \\
\text { of total } \\
\text { body } \\
\text { length }\end{array}$} & \multicolumn{3}{|c|}{ Fifth Avenue Hospital (A) } & \multicolumn{3}{|c|}{ Bellevue Hospital (B) } & \multirow[b]{2}{*}{$\begin{array}{l}\text { Difference } \\
\text { Group A minus } \\
\text { Group B and } \\
\text { probable enror } \\
\text { (difference) }\end{array}$} & \multirow{2}{*}{$\begin{array}{l}\text { Difference } \\
\text { divided } \\
\text { by } \\
\text { probable } \\
\text { error } \\
\text { (difference) }\end{array}$} \\
\hline & 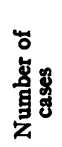 & $\begin{array}{l}\text { Average and } \\
\text { probable error }\end{array}$ & 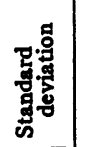 & 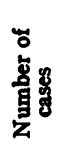 & $\begin{array}{l}\text { Average and } \\
\text { probable error }\end{array}$ & 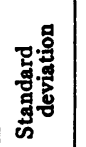 & & \\
\hline$m m$. & & $m m$. & mm. & & mm. & $m m$. & mm. & \\
\hline $450-499$ & 23 & $115.2 \pm 0.65$ & 4.66 & 12 & $116.0 \pm 1.10$ & 5.66 & $-0.8 \pm 1.27$ & -0.7 \\
\hline $500-549$ & 69 & $124.8 \pm 0.47$ & 5.78 & 42 & $121.3 \pm 0.62$ & $6.00 \mid$ & $3.5 \pm 0.78$ & 4.5 \\
\hline $550-599$ & 60 & $136.4 \pm 0.54$ & 6.16 & 22 & $127.8 \pm 0.88$ & 6.10 & $8.6 \pm 1.03$ & 8.3 \\
\hline $600-649$ & 54 & $147.1 \pm 0.63$ & 6.84 & 22 & $145.5 \pm 0.84$ & 5.86 & $1.6 \pm 1.05$ & 1.5 \\
\hline $650-699$ & 66 & $160.9 \pm 0.49$ & 5.98 & 23 & $157.0 \pm 0.95$ & 6.72 & $3.9 \pm$ & 3.6 \\
\hline $700-749$ & 55 & $172.7 \pm 0.79$ & 8.68 & 31 & $169.4 \pm 0.79$ & 6.52 & $3.3 \pm 1.12$ & 2.9 \\
\hline
\end{tabular}

The difference between the two groups of infants are not dependent on differences in race, since as shown above, this was found to be without influence on the proportions of the body dimensions in this series. Nor does it seem likely that technical errors in making measurements, dependent on the greater amount of subcutaneous fat in the Group A infants, can account for the differences found. The factor of muscle tonus variations has also been considered (1) and has 


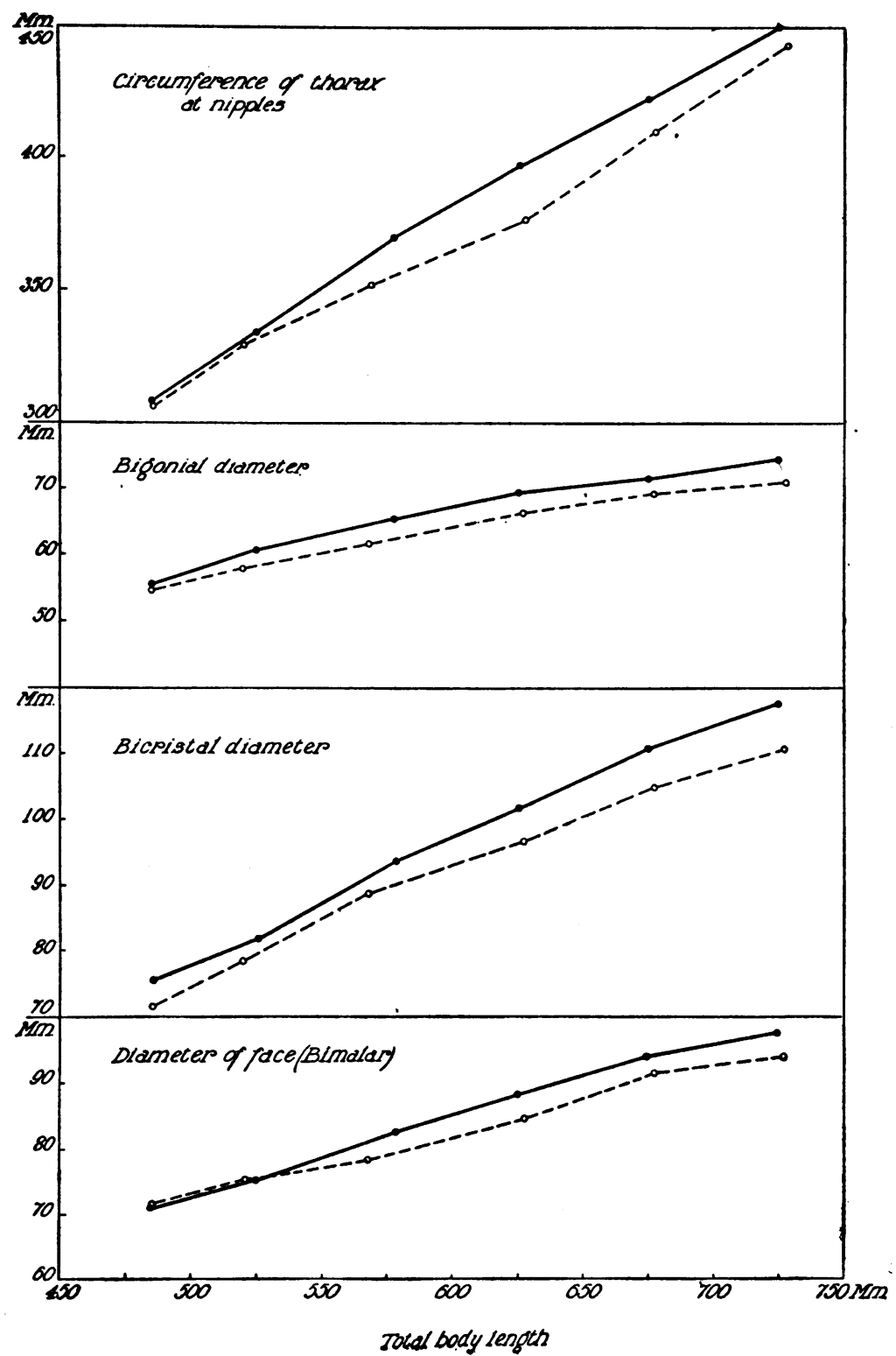

Chart 5. Comparison of the Proportions of Vartous Dimensions of Fifth Avenue and Bellevue Hospital Infants

The solid lines connect the average points for Fifth Avenue Hospital infants, the broken lines the Bellevue Hospital infants. 
been found to be without influence in explaining differences in the proportions of the dimensions of the two groups.

COMMENT

Accompanying the delay in weight gain of infants from poor homes there is a retardation in the growth of the linear measurements. This is more marked for the transverse diameters, (facial diameter, bigonial diameter, biacromial diameter and bicristal diameter) and for

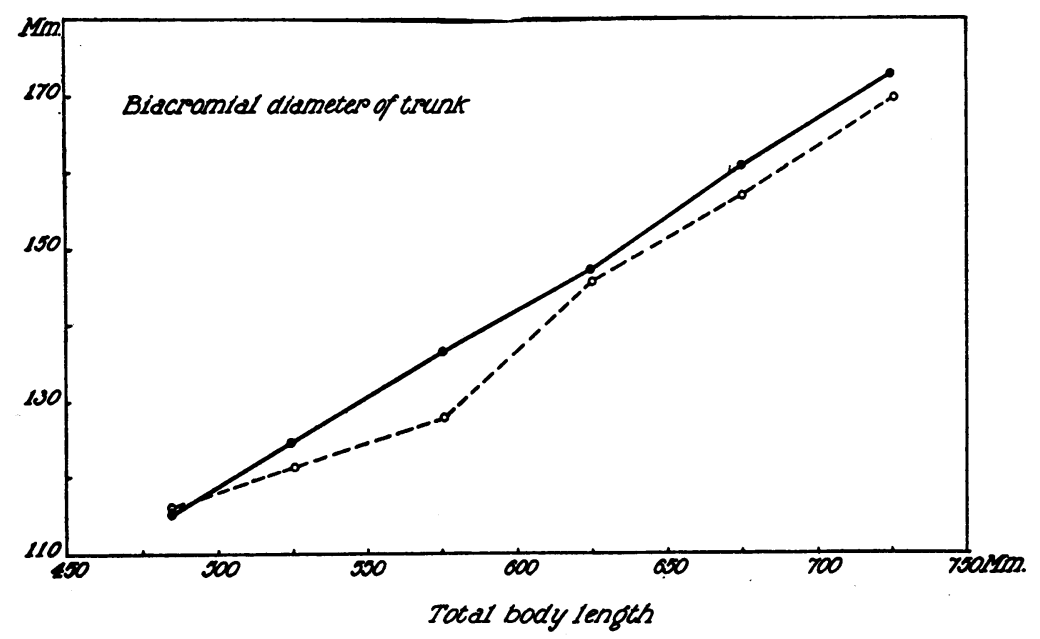

Chart 6. Comparison of the Proportions of the Biacromial Diameter of Fifth Avenue and Bellevue Hospital Infants

The solid lines connect the average points for Fifth Avenue Hospital infants, the broken lines the Bellevue Hospital infants.

the circumference of the thorax, than for the cephalocaudal or vertical dimensions (total body length, upper facial height, length of humerus, radius, femur and tibia). There results a change in the proportions of the external dimensions, the infants from poor families becoming relatively narrower than infants from families of moderate income. It seems reasonable to assume that this change is dependent on the environmental factors implied in the difference in the social condition. The factors influencing growth and development at this age, such as diet, atmospheric conditions and infection all vary with the social condition. 
Racial differences (Caucasians only), if they play any part in determining body build in infants, were too small to be apparent in this study.

It is not possible to say whether these changes in body build are permanent. That they are profound and clinically significant will be shown in the paper on the relationship between body build and disease during infancy.

The changes in body build here noted recall the well known observations of Boas (5), who found a change in body build of American born children of immigrants.

\section{SUMMARY}

1. Measurements of the external dimensions of 2 groups of healthy infants under 1 year have been made.

2. One group was observed, for the most part, at a special clinic at the Fifth Avenue Hospital. The infants came from families of moderate income and received diets adequate in the known essential food substances at an early age. The second group, many of whom were foundlings, was observed at Bellevue Hospital. The infants came from very poor families and their diets were probably inadequate in several of the known essential food substances as well as in the total intake of energy-yielding foods.

3. After the first month and at least until the end of the first year of life (calculations have been made only for the first year of life) the infants from the poor homes (Bellevue district) weighed less and were shorter in stature than those from the better homes (Fifth Avenue Hospital patients).

4. Using total body length as a base line empirical formulae have been computed for curves of central tendency for the various external dimensions of the bodies of the infants from homes of moderate incomes.

5. Above $550 \mathrm{~mm}$. in body length infants from the poorer homes are smaller, relative to total body length, in their transverse diameters and in the circumference of the thorax, than are infants from better homes. The retardation in the growth of the external dimensions, accompanying the delay in weight gain, is greater for the transverse than for the cephalocaudal, or vertical dimensions. 
6. No differences in the proportion of the external dimensions of the body due to race (Caucasians only) were apparent in this series.

\section{BIBLIOGRAPHY}

1. Bakwin, H. and Bakwin, R. M., J. Clin. Invest., 1931, x, 369. Body Build in Infants. I. The Technique of Measuring the External Dimensions of the Body in Infants.

2. Scammon, R. E. and Rucker, W. H., Am. J. Dis. Child., 1921, xxi, 552. Changes in the Form and Dimensions of the Chest at Birth, and in the Neonatal Period.

3. Holt, L. E. and Howland, J., Diseases of Infancy and Childhood. D. Appleton and Company, New York, 1928, 9th ed., p. 13.

4. Scammon, R. E. and Calkins, L. A., Univ. Minn. Press, 1929. The Development and Growth of the External Dimensions of the Human Body in the Fetal Period.

5. Boas, F., Changes in Bodily Form of Descendants of Immigrants. New York, Columbia University Press, 1912. 